\title{
A COMPARATIVE STUDY OF PULMONARY FUNCTION TEST ABNORMALITIES IN RHEUMATOID ARTHRITIS-TREATMENT NAIVE VERSUS PATIENTS ON TREATMENT
}

\author{
Karthikeyan Dakshinamoorthy1, Arunkumar Azhaganantham²
}

${ }_{1}^{1}$ Assistant Professor, Department of General Medicine, Sri Venkateshwaraa Medical College Hospital and Research Centre, Puducherry, India.

${ }^{2}$ Assistant Professor, Department of General Medicine, Sri Venkateshwaraa Medical College Hospital and Research Centre, Puducherry, India.

\begin{tabular}{l}
\hline ABSTRACT \\
BACKGROUND \\
Rheumatoid Arthritis (RA) is a chronic systemic inflammatory disease characterized by persistent synovitis of most of the \\
peripheral joints. Pulmonary involvement is one of the important extra articular features of RA with worse prognosis. Current \\
research aimed to compare the pulmonary function test abnormalities in RA patients- treatment naïve versus patients on \\
treatment.
\end{tabular}

\section{MATERIALS AND METHODS}

50 rheumatoid arthritis patients were divided into two groups - treatment naïve group \& on treatment group and evaluated for lung involvement by spirometry. Those patients showing lung function abnormalities were evaluated for correlation with various characteristics like age, gender, duration of treatment, pattern of PFT abnormality and the severity of arthritis.

\section{RESULTS}

PFT abnormalities were found in more than half of RA patients with restrictive pattern of lung disease being the commonest abnormality in females. There is increased prevalence of PFT abnormality in 'on treatment' group when compared to treatment naïve group.

\section{CONCLUSION}

Lung involvement is one of the most important extraarticular manifestations of rheumatoid arthritis. Pulmonary function test (PFT) helps in identifying the lung involvement and its pattern in rheumatoid arthritis patients.

\section{KEY WORDS}

Rheumatoid Arthritis, Pulmonary Function Test, Obstructive and Restrictive Lung Disease.

HOW TO CITE THIS ARTICLE: Dakshinamoorthy K, Azhaganantham A. A comparative study of pulmonary function test abnormalities in rheumatoid arthritis-treatment naive versus patients on treatment. J. Evolution Med. Dent. Sci. 2018;7(48):51805183, DOI: $10.14260 /$ jemds/2018/1149

\section{BACKGROUND}

Rheumatoid arthritis (RA) is a chronic systemic inflammatory disease characterized by persistent synovitis of most of the peripheral joints depending on the duration of disease causing cartilaginous and bony erosions. The clinical course is usually lifelong affliction with intermittent remissions and exacerbations. ${ }^{1}$ RA is found in $1-2 \%$ of general population seen more commonly in the age group of $40-50$ years and its prevalence increases with advancing age. 2 The mortality and morbidity of RA is mostly attributed to its extra articular involvement seen in nearly $50 \%$ of patients with RA. The most commonly affected sites being affected are the skin, eye, heart, and lungs. ${ }^{3}$

Pulmonary involvement is one of the important extra articular features being the second most common cause of death $(18 \%)$ in patients affected with RA. ${ }^{4}$ It occurs in the form of pleural diseases, pulmonary nodule, interstitial lung

'Financial or Other Competing Interest': None.

Submission 14-10-2018, Peer Review 08-11-2018,

Acceptance 14-11-2018, Published 26-11-2018.

Corresponding Author:

Dr. Karthikeyan Dakshinamoorthy,

Plot No. 7, Fourth Cross Street,

Balaji Nagar, Oulgaret-605010

Puducherry, India.

E-mail: karthi.chelsea@gmail.com

DOI: $10.14260 /$ jemds $/ 2018 / 1149$

\section{(c) $(1)$}

diseases, airway obstruction and pulmonary vascular disease apart from drug-induced lung injury. ${ }^{5}$ Pulmonary function test (PFT) abnormalities in RA can be restrictive (19-44\%) if there is pleural or parenchymal involvement, or obstructive $(16-38 \%)$ if there is obliterated bronchiolitis, bronchiectasis or cricoarytenoid arthritis. ${ }^{6}$

The incidence of pulmonary function test abnormalities in various studies done in patients with RA varies widely. Although the patients with RA have varying degree of severity in the manifestation of pulmonary function, the progression of the disease severity may or may not be altered by the immunosuppressive therapy. Lung involvement in RA carries a worse prognosis ${ }^{7}$. Hence the present study was designed to assess the prevalence and type of PFT abnormality in patients with rheumatoid arthritis presenting to a tertiary care hospital and also to compare the type of PFT abnormalities between treatment naïve and on treatment group.

\section{MATERIALS AND METHODS}

This was a cross sectional study conducted at a tertiary care hospital in Madurai. The study participants were known cases of rheumatoid arthritis patients attending medicine and rheumatology outpatient department satisfying the 2010 ACR/ EULAR criteria for classification of RA. Total of 50 patients were selected. As it is a pilot study, we took only 50 
patients. Group I consisted of 25 RA patients who were treatment naïve (i.e. newly diagnosed and not on any treatment) and Group II consisted of 25 RA patients who were on some treatment for RA. Each group had 25 equal numbers, so it would be useful for comparison.

Patients who were diagnosed to have either of bronchial asthma/ chronic obstructive Airway disease, Current/ past pulmonary tuberculosis, any occupational lung disease, or any severe disease interfering with performance of pulmonary function test were excluded from the study. The selected patients were evaluated with a detailed history regarding duration of disease, rheumatoid functional status, occupation history, smoking history, drug history and respiratory symptoms like breathlessness, cough with or without sputum production, pleuritic chest pain. Presence of joint swelling, tenderness, deformities and number of tender joints were noted. Rheumatological functional status and a detailed respiratory system examination along with spirometric evaluations.

All the data were recorded in a case report form and analysed using descriptive statistics. Categorical data were compared with Pearson chi square tests using SPSS statistical software version 23. Significance was defined by P values less than 0.05 using a two-tailed test.

\section{RESULTS}

50 patients with rheumatoid arthritis who presented to Madurai medical college, Madurai over a period of 4 months were included the study. This included 34 females and 15 males [M: F ratio 1:2], where almost $34(68 \%)$ of them belonged to the age group 40-60 years of age. Only 8 patients had respiratory symptoms which included dry cough $5(10 \%)$ patients, wheezing $2(4 \%)$, and nasal allergy $1(2 \%)$. Out of 25 patients 13 patients were on methotrexate treatment for $3-6$ years and 12 were on methotrexate treatment for more than 6 years.

PFT abnormality serves to identify whether a lung disease is of obstructive or restrictive pattern. In treatment naïve group (Group 1), 14 (56\%) of patients had abnormal PFT which showed obstructive pattern in $4(16 \%)$ RA patients and restrictive pattern in 10 (40\%) RA patients. The severity of obstructive pattern was mild in $2(8 \%)$ patients and moderate in $2(8 \%)$ patients whereas the severity of restrictive pattern was mild in $9(36 \%)$ and moderate in 1 (4\%) patient.

In the treatment group (Group 2), 16 (64\%) of patients had abnormal PFT which showed obstructive pattern in 5 (20\%) RA patients and restrictive pattern in 11 (44\%) RA patients. The severity of obstructive pattern was mild in 4 (16\%) patients and severe in 1 (4\%) patient whereas the severity of restrictive pattern was mild in $8(32 \%)$, moderate in $2(8 \%)$ patient and severe in $1(4 \%)$ patient.

It was found that more female patients had restrictive pattern PFT abnormality when compared to male patients with a statistical significance of $p<0.0001$. The incidence of PFT abnormality in the age group of 50 to 59 years was high when compared to any other age group which was also found to be statistically significant. No statistical correlation was found between the severity of PFT abnormality and duration of disease.

\begin{tabular}{|c|c|c|c|}
\hline \multicolumn{2}{|c|}{ Parameters } & $\begin{array}{c}\text { Treatment } \\
\text { Naïve Group } \\
(n=25)\end{array}$ & $\begin{array}{c}\text { On Treatment } \\
\text { Group } \\
(\mathrm{n}=25)\end{array}$ \\
\hline \multirow{3}{*}{ Age } & $<40$ years & 5 & 6 \\
\hline & 40-60 years & 17 & 17 \\
\hline & $>60$ years & 3 & 2 \\
\hline \multirow{2}{*}{ Gender } & Male & 4 & 12 \\
\hline & Female & 21 & 13 \\
\hline \multirow{2}{*}{$\begin{array}{l}\text { Duration of } \\
\text { treatment }\end{array}$} & 3-6 years & 0 & 13 \\
\hline & $\begin{array}{c}\text { More than } 6 \\
\text { years }\end{array}$ & 0 & 12 \\
\hline \multicolumn{4}{|c|}{$\begin{array}{l}\text { Table 1. Age \& Gender Distribution, and } \\
\text { Treatment Duration of Subjects }\end{array}$} \\
\hline
\end{tabular}

\begin{tabular}{|c|c|c|}
\hline \multirow[t]{2}{*}{ PFT Finding } & \multicolumn{2}{|c|}{ Frequency (\%) } \\
\hline & $\begin{array}{c}\text { Treatment Naïve } \\
\text { Group }\end{array}$ & $\begin{array}{l}\text { On Treatment } \\
\text { Group }\end{array}$ \\
\hline Obstruction & $4(16 \%)$ & $5(20 \%)$ \\
\hline Restriction & $10(40 \%)$ & $11(44 \%)$ \\
\hline Normal & $11(44 \%)$ & $9(36 \%)$ \\
\hline Total & 25 & 25 \\
\hline \multicolumn{3}{|c|}{$\begin{array}{c}\text { Table 2. PFT Abnormalities in Patients with } \\
\text { RA Type and Severity }\end{array}$} \\
\hline
\end{tabular}

\begin{tabular}{|c|c|c|c|c|c|c|c|}
\hline \multirow{3}{*}{ } & \multicolumn{6}{|c|}{ Age in Years } & \multirow[b]{3}{*}{ 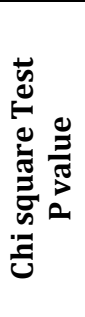 } \\
\hline & \multicolumn{2}{|c|}{$<40$ Years } & \multicolumn{2}{|c|}{ 40-60 Years } & \multicolumn{2}{|c|}{$>60$ Years } & \\
\hline & 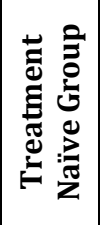 & 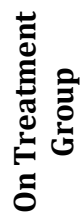 & 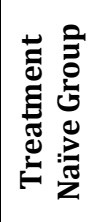 & 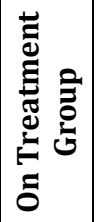 & 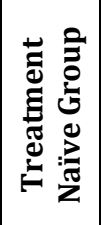 & 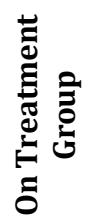 & \\
\hline Obstruction & 0 & 0 & $\begin{array}{c}4 \\
(16 \%)\end{array}$ & $\begin{array}{c}4 \\
(16 \%)\end{array}$ & 0 & $\begin{array}{c}1 \\
(4 \%)\end{array}$ & \\
\hline Restriction & $\begin{array}{c}2 \\
(8 \%)\end{array}$ & $\begin{array}{c}2 \\
(8 \%)\end{array}$ & $\begin{array}{c}7 \\
(28 \%)\end{array}$ & $\begin{array}{c}8 \\
(32 \%)\end{array}$ & $\begin{array}{c}2 \\
(8 \%)\end{array}$ & $\begin{array}{c}2 \\
(8 \%)\end{array}$ & \\
\hline Normal & $\begin{array}{c}3 \\
(12 \%)\end{array}$ & $\begin{array}{c}4 \\
(16 \%)\end{array}$ & $\begin{array}{c}6 \\
(24 \%)\end{array}$ & $\begin{array}{c}5 \\
(20 \%)\end{array}$ & $1(4 \%)$ & 0 & \\
\hline
\end{tabular}

*- Highly significant.

\begin{tabular}{|c|c|c|c|c|c|}
\hline \multirow{3}{*}{ 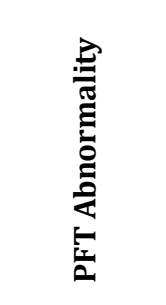 } & \multicolumn{4}{|c|}{ Gender } & \multirow[b]{3}{*}{ 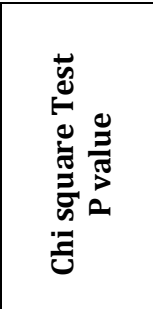 } \\
\hline & \multicolumn{2}{|c|}{ Male } & \multicolumn{2}{|c|}{ Female } & \\
\hline & 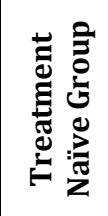 & 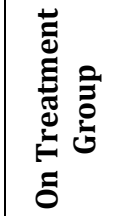 & 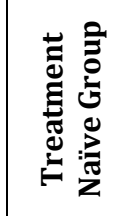 & 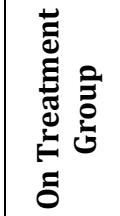 & \\
\hline Obstruction & $2(8 \%)$ & $5(20 \%)$ & $2(8 \%)$ & 0 & 0.744 \\
\hline Restriction & $2(8 \%)$ & $4(16 \%)$ & $8(32 \%)$ & $7(28 \%)$ & (not \\
\hline Normal & 0 & $2(8 \%)$ & $11(44 \%)$ & $7(28 \%)$ & significant) \\
\hline
\end{tabular}

\section{DISCUSSION}

Rheumatoid arthritis (RA) is a chronic multi-system inflammatory disease which can be associated with a lung disease of obstructive or restrictive pattern. Pulmonary dysfunction in RA is associated with worse prognosis. In this study on 50 RA patients, $30(60 \%)$ had abnormal lung function test. Among them, $16 \%$ had obstructive and $40 \%$ had restrictive pattern in treatment naïve group whereas $20 \%$ had obstructive and $44 \%$ had restrictive pattern in on 
treatment group. The prevalence of restrictive PFT abnormality was more common in female patients. However, the prevalence of ILD and pleural involvement that causes restriction is more common in men a study conducted by Gabbay et al. ${ }^{8}$ Majority of patients with PFT abnormality in this study were in the fifth and sixth decades which was similar to a study by Raniga et $\mathrm{al}^{9}$ and Fuld et al.10

PFTs were more sensitive in detecting pulmonary abnormalities than chest radiographs. However, when both these investigations were used together, the yield of pulmonary abnormalities was better than either test alone. The incidence of radiological abnormality ranges from $2-10 \%$ in patients with RA. Raniga et $\mathrm{al}^{9}$ stated that abnormalities detectable on chest radiograph were $13.33 \%$ showing changes consistent with ILD in $4 / 30$ (13.3\%) including bilateral reticular infiltrates in three and honeycombing in one and x-ray chest was normal in $7 / 11$ (63.6\%) patients with HRCT positive ILD.

In a study conducted by Perez et al, 11 evidence of interstitial fibrosis in chest radiography was seen approximately $5 \%$ of RA patients and at HRCT in $30 \%-40 \%$. The chest radiograph may be normal in patients with early fibrosis and most of these patients had respiratory symptoms. In a study conducted by Vitali et al,12 the prevalence of ground glass opacities (GGOs) on HRCT in patients without respiratory symptoms was only $3 \%$ and none had honeycombing, in contrast to $26 \%$ and $23 \%$ respectively in patients with respiratory symptoms. Chest radiograph is the least sensitive in detecting interstitial lung disease. The ability of PFTs to pick up an abnormality in this study was better than the chest radiograph which were $52 \%$ and $10.7 \%$ respectively. However, when both these investigations were combined, the sensitivity was better than either test alone.

In late stages, chest radiograph showed changes identical to that of Interstitial Pulmonary Fibrosis (IPF). Chest radiographs typically show a fine reticular or reticulonodular pattern involving the lower lung zones in early stages. With progression of disease, the reticular pattern becomes more coarse and diffuse, and honey combing might be seen. In this study the reticulonodular opacity consistent with ILD was seen in $3(4 \%)$ of patients. This accounted for $37.5 \%$ of the abnormal chest radiographs. The radiological abnormality was in the form of reticulonodular opacity consistent with the diagnosis of ILD. HRCT showed evidence of interstitial lung disease in eleven out of thirty patients and so the most sensitive of all parameters. It was evident that chest radiograph is the least sensitive in detecting interstitial lung disease. The disparity in abnormal findings in chest X-ray changes and in lung function tests suggests that in examining pulmonary manifestations in patients with RA, both radiographic methods and pulmonary function tests should be used for relevant evaluation.

The number of patients with restriction in treatment naive group was $40 \%$ and in on treatment group was $44 \%$. There was no correlation between severity of PFT abnormality and the duration of disease. Cervantes-Perez et $\mathrm{al}^{13}$ and no correlation was found between the disease duration, the number of patients and the severity of restrictive PFT abnormality. This could be explained by the fact that most of the patients might have had subclinical ILD when compared to the series of Cervantes-Perez et al. The number of patients with obstructive PFTs increased as the disease duration increased. However, there was no correlation observed between the disease duration and severity of PFT abnormality which was similar to a study conducted by Fuld et al.10 A strong association between pulmonary diseases in RA and cigarette smoking was established in this study.

Methotrexate is one of the most common first line DMARDs (Disease modifying anti rheumatoid drugs) used in the management of RA. Methotrexate induced acute pneumonitis is a life-threatening condition encountered in $0.3-11.6 \%$ of RA patients treated with methotrexate during the first 6 months. None of the patient in this study reported to have acute pneumonitis. Khadadah et $\mathrm{al}^{14}$ and Beyeler et al15 stated a significant deterioration in lung function after 2years of treatment with methotrexate which raised the issue of chronic toxicity, but Dawson et al found no such deterioration in lung function over 2 years with methotrexate. There was no correlation observed between the duration of DMARDs and PFT abnormality in this study. However, a longitudinal study is warranted to assess the impact of long-term methotrexate and chronic lung toxicity.

\section{CONCLUSION}

Lung involvement is one of the most important extra articular manifestations of rheumatoid arthritis. PFTs are a sensitive tool in picking up pulmonary involvement in rheumatoid arthritis. PFT abnormalities were found in more than half of RA patients with restrictive pattern of lung disease being the commonest abnormality in females. There is increased incidence of PFT abnormality in on treatment group when compared to treatment naïve group.

\section{REFERENCES}

[1] Lipsky PE. Harrison's principles of internal medicine. Vol. 2. 20 $0^{\text {th }}$ edn. McGraw-Hill 2018: p. 1928-37.

[2] Kasper DL, Braunwald E. Rheumatoid Arthritis. Harrison's principles of internal medicine. Vol. 2. $20^{\text {th }}$ edn. McGraw-Hill 2018: p. 1968.

[3] Firestein GS. Etiology and pathogenesis of rheumatoid arthritis. In: Ruddy S, Harris E, Sledge C, eds. Kelly's textbook of rheumatology. $6^{\text {th }}$ edn. Philadelphia: WB Saunders 2001: p. 921-66.

[4] Boers M, Dijkmans B, Gabriel S, et al. Making an impact on mortality in rheumatoid arthritis: targeting cardiovascular comorbidity. Arthritis Rheum 2004;50(6):1734-9.

[5] Provenzano G. Chronic pulmonary toxicity of methotrexate and rheumatoid arthritis. Rheumotology (Oxford) 2003;42(6):802-3.

[6] Helmers R, Galvin J, Hunninghake GW. Pulmonary manifestations associated with rheumatoid arthritis. Chest 1991;100(1):235-8.

[7] Caplan A. Certain unusual radiological appearances in the chest of coal miners suffering from rheumatoid arthritis. Thorax 1953;8(1):29-37.

[8] Gabbay E, Tarala R, Will R, et al. Interstitial lung disease in recent-onset rheumatoid arthritis. Am J Respir Crit Care Med 1997;156(2 Pt 1):528-35.

[9] Raniga S, Sharma P, Kaur G, et al. Interstitial Lung disease (ILD) in Rheumatoid arthritis (RA) - a study of thirty cases. Ind J of Radiol Imag 2006;16(4):835-9. 
[10] Fuld JP, Johnson MK, Cotton MM, et al. A longitudinal study of lung function in non-smoking patients with rheumatoid arthritis. Chest 2003;124(4):1224-31.

[11] Perez T, Remy-Jardin M, Cortet B. Airways involvement in rheumatoid arthritis: clinical, functional and HRCT findings. Am J Respir Crit Care Med 1998;157(5 Pt 1):1658-65.

[12] Vitali C, Viegi G, Tassoni S, et al. Lung function abnormalities in different connective tissue diseases. Clin Rheumatol 1986;5(2):181-8.
[13] Cervantes-Perez C, Toro-Perez AH, Rodriguez-Jurado P. Pulmonary involvement in rheumatoid arthritis. JAMA 1980;243(17):1715-9.

[14] Khadadah ME, Jayakrishnan B, Al-Gorair S, et al. Effect of methotrexate on pulmonary function in-patients with rheumatoid arthritis - a prospective study. Rheumatol Int 2002;22(5):204-7.

[15] Beyeler C, Jordi B, Gerber NJ, et al. Pulmonary function in rheumatoid arthritis treated with low-dose methotrexate: a longitudinal study. Br J Rheumatol 1996;35(5):446-52. 